\title{
MODELLING OF COVER CONCRETE CRACKING DUE TO UNIFORM CORROSION OF REINFORCEMENT
}

\author{
Sheikh Shakib* and Abu Zakir Morshed \\ Department of Civil Engineering, Khulna University of Engineering \& Technology, Khulna - 9203, Bangladesh
}

Received: 07 May 2019

Accepted: 19 November 2020

\begin{abstract}
Cracking of cover concrete due to the corrosion of reinforcing steel is one of the main causes of deterioration in Reinforced Concrete (RC) structures. An outbound stress is developed in concrete surrounding the reinforcing steels due to the expansive corrosion products of reinforcement leading to cracking of the concrete cover. In this paper, the cracking pressure was simulated through a finite element modeling. The effect of geometrical and material parameters, i.e. concrete cover thickness, bar diameter, and concrete tensile strength, on the cracking pressure was also investigated. Abaqus 6.14 was used as modeling platform. The cracking pressure was found to dependent on the cover thickness and tensile strength of concrete. A higher pressure was required to initiate crack for a higher cover thicknesses and tensile strength. The cracking pressure was decreased with the increase in bar diameter. Finally the crack initiation and propagation has been simulated successfully for different arrangements of reinforcements.
\end{abstract}

Keywords: Corrosion; Cracking Pressure; Concrete Cover; Crack Propagation; Reinforced Concrete.

\section{INTRODUCTION}

Concrete, a durable composite material because of having high alkaline pore solution (Mundra et al., 2017; Bažant, 1979). The high alkalinity attained as a result of cement hydration. In case of reinforced concrete structures, in the presence of solution, a thin layer of $\mathrm{Fe}_{2} \mathrm{O}_{3}$ forms on the surface of rebars. This layer, also known as layer of passivation, protects the reinforcement from aggressive weather (Bažant 1979; Glasser and SagoeCrentsil, 1989; Val et al., 2009). Corrosion is one of the most deteriorative mechanism in the saline weather conditions. The chlorides penetrate through the pore spaces of the concrete and accumulates around the reinforcement. At a certain level of accumulation, the layer of passivation destroyed consequences an initiation if corrosion process. This process is an electrochemical process. In which, electrochemical microcells are produced and the rebars continues to corrode. In the reaction process, different types of oxides are formed which were found to be larger volume than the rebar material (Pantazopoulou and Papoulia, 2001; Liu and Weyers, 1998). These expansive products thus impose an outward thrust on the surrounding concrete. Tensile stresses are developed in the surrounding concrete because of this expansive thrust. Concrete is weak in tension which causes the initiation and propagation of cracks (Bhargava et al., 2006). The location of crack initiation depends on the cover thickness (Shakib and Morshed, 2019). In this research, mechanism of cracking was investigated through finite element modelling.

Corrosion is a complex mechanism especially in concrete environment. Last few decades, a lot of works related to corrosion of reinforcement have conducted both experimentally and numerically (Bazant, 1979; Bhargava et al., 2006; Liu and Weyers, 1998; Pantazopoulou and Papoulia, 2001). The researchers tried to figure out the cracking mechanism and cracking pattern due to corrosion of rebars numerically (Dagher and Kulendran, 1987; Du et al., 2006; Val et al., 2009). Most of them explained the crack initiation mechanism as- when the circumferential stress, developed by the expansive oxides, exceeds the concrete tensile strength crack initiates and propagate towards the cover surface. But there is an effect of clear cover thickness on the crack initiation mechanism. This research focused on this point. A commercial software, ABAQUS was employed as modelling platform. The model regarded a uniform corrosion of reinforcement. The model predicted the initiation and propagation phenomena for a single bar as well as couple of bars successfully.

\section{METHODOLOGY}

\subsection{Constitutive Modelling of Concrete}

The software, ABAQUS, is capable of modelling the fracture of concrete material in three different techniques; smeared crack model (SCM), concrete damaged plasticity model (CDP), and brittle cracking model (BCM). Of the three approaches concrete damaged plasticity model was selected in this study for its robustness in applying to model cracks. To characterize the constitutive behaviour of concrete, four different laws are needed to be defined; compressive and tensile behaviour of concrete, damage function, yield function, and flow rule. 
The behaviour of concrete in uniaxial compression and tension considered in the CDP model is shown in Figure 1. In case of compression, a linear-elastic response is considered till the initial yield point, $\sigma \mathrm{c} 0$. Whereas, in tension, a linear stress strain relationship is considered up to the ultimate stress, $\sigma_{t 0}$. In the post-peak region (plastic region), the unloading curve shows a degraded stiffness both in compression and tension. This degradation is due to the damage of material. The model introduces two damage variables, $d_{c}$ and $d_{t}$, to define this degradation. The range of this variables is 0 to 1 depending on the level of damage. Zero represents "undamaged" and one represents "fully damaged". $E_{0}$ is the initial (undamaged) modulus of elasticity of concrete. $\varepsilon_{c}^{i n}$ and $\varepsilon_{c}^{p l}$ are compressive inelastic and plastic strain, and $\varepsilon_{t}^{c k}$ and $\varepsilon_{t}^{p l}$ are tensile cracking and plastic strain, respectively. The stress-strain behaviour both in compression and tension are considered as the following equations (Abaqus user manual)

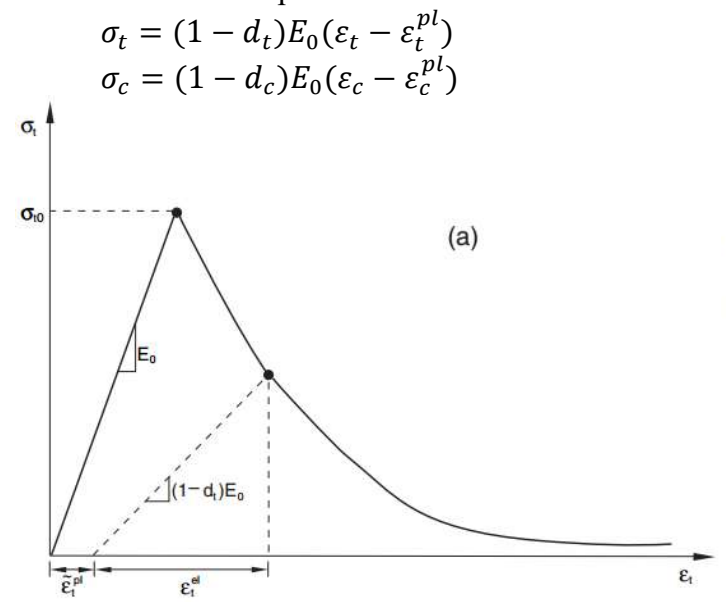

Figure 1: Stress-strain behaviour in tension (a) and compression (b).

Tensile cracking and compressive crushing are the two failure mechanisms considered in the CDP model. In these mechanisms, the failure surfaces are controlled by the tensile and compressive plastic strains $\left(\varepsilon_{t}^{p l}\right.$ and $\left.\varepsilon_{c}^{p l}\right)$ as shown in Figure 2. These strains are automatically calculated in the software from the cracking strain and inelastic strain $\left(\varepsilon_{t}^{c k}\right.$ and $\left.\varepsilon_{c}^{i n}\right)$ following the equations.

$$
\begin{aligned}
\varepsilon_{t}^{p l} & =\varepsilon_{t}^{c k}-\frac{d_{t}}{1-d_{t}} \frac{\sigma_{t}}{E_{0}} \\
\varepsilon_{c}^{p l} & =\varepsilon_{c}^{i n}-\frac{d_{c}}{1-d_{c}} \frac{\sigma_{c}}{E_{0}}
\end{aligned}
$$
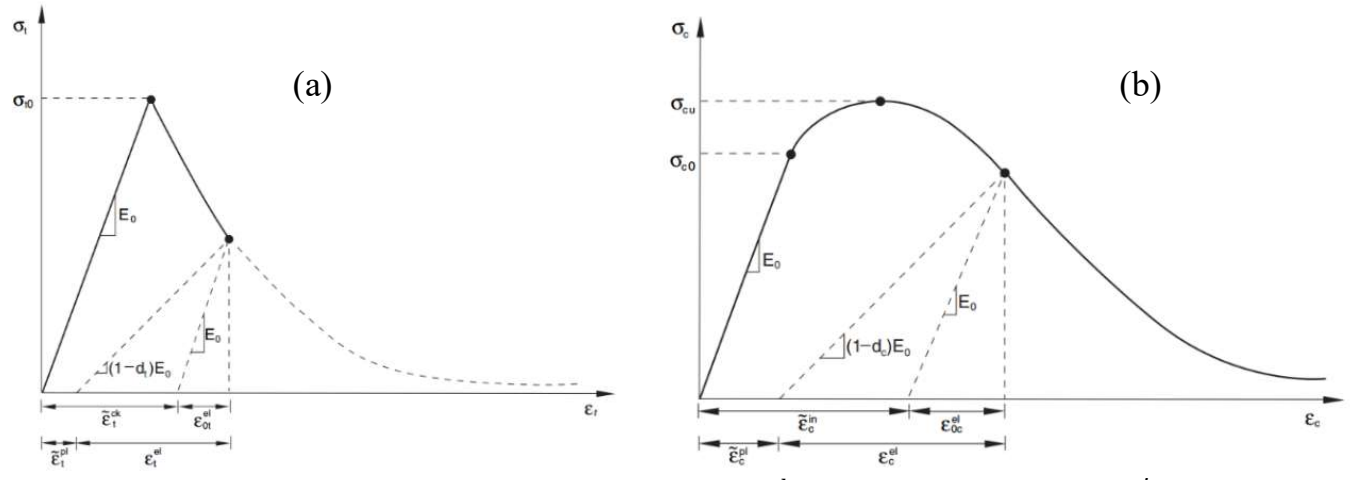

Figure 2: Definition of (a) cracking strain $\left(\varepsilon_{t}^{c k}\right)$ and (b) inelastic strain $\left(\varepsilon_{c}^{i n}\right)$

The CDP model uses the modified by Lee and Fenves (1998) yield function of Lubliner et al. (1989) to define the failure surface. Two model inputs are needed to define the yield function in the model; the ratio of biaxial to uniaxial compressive stress $\left(\frac{\sigma_{b 0}}{\sigma_{c 0}}\right.$ default value is 1.16) and the ratio of the tensile and compressive second invariant $\left(K_{c}\right.$, default value is $\left.2 / 3\right) . K_{c}$ controls the shape of failure surface in the deviatory plane having a wide range of values, $0-1$, as shown in Figure 3. A non-associated plastic flow is presumed by CDP model where the DruckerPrager hyperbolic function is used as flow potential. The function is as follows

$$
G=\sqrt{\left(\in \sigma_{t} \tan \psi\right)^{2}+q^{2}}-p \tan \psi
$$

Where, $\psi=$ dilation angle which is measured in the $\mathrm{p}-\mathrm{q}$ plane at high confining pressure; $\epsilon=$ eccentricity. The default value of eccentricity is 0.1 . 


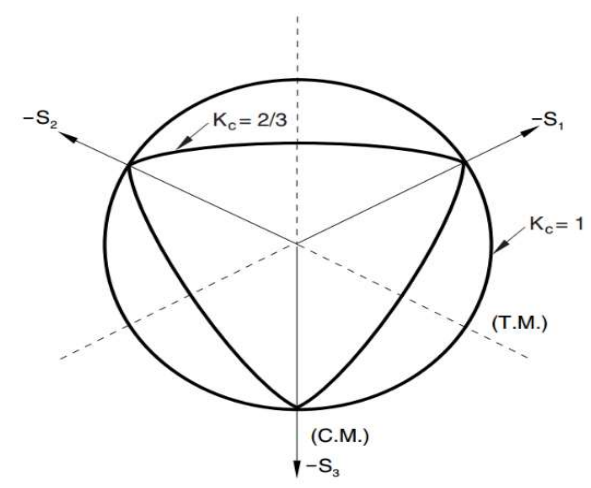

Figure 3: Yield surfaces for different values of $K_{c}$ in the deviatoric plane

\subsection{Input Parameters of the Model}

The CDP model requires the values of and $K_{c}$ to define the yield function as well as $\psi$ and $\epsilon$ to define flow rule. This model made use the default values of $\frac{\sigma_{b 0}}{\sigma_{c 0}}, K_{c}$, and $\epsilon$ as shown in Table 1. A dilation angle of $30^{0}$ is considered in this study. A special parameter, viscosity parameter, needs to be defined in the model which controls the convergence of model. The value of this parameter is selected by trial method.

Table 1: Parameters for CPDM

\begin{tabular}{ccccc}
\hline$\psi$ & $\epsilon$ & $\frac{\sigma_{b 0}}{\sigma_{c 0}}$ & $K_{c}$ & Viscosity Parameter \\
\hline $30^{0}$ & 0.1 & 1.16 & $2 / 3$ & 0.0001 \\
\hline
\end{tabular}

Two different parameters, modulus of elasticity $\left(E_{c}\right)$ and Poisson's ratio are to be input to define the elastic property of the material. In this study, 0.2 is chosen as the Poisson's ratio. The $E_{c}$ was calculated by the equation given by ACI 318 as follows

$$
E_{c}=57000 \sqrt{f_{c}^{\prime}} \text { psi }
$$

To define the stress-strain relationship in compression, the model proposed by Popovics, (1973) was used in this study. The relationship is shown in the following equation,

$$
\frac{f_{c}}{f_{c}^{\prime}}=\frac{n\left(\frac{\varepsilon_{C}}{\varepsilon_{C 0}}\right)}{(n-1)+\left(\frac{\varepsilon_{C}}{\varepsilon_{C 0}}\right)^{n}}
$$

Where $f_{c}^{\prime}, \varepsilon_{c 0}$ are the compressive strength and strain corresponding to the maximum stress, respectively. The ' $\mathrm{n}$ ' is defined by,

$$
n=0.4 \times 10^{-3} f_{c}^{\prime}(p s i)+1.0
$$

Whereas, the stress-strain behaviour in tension was presumed linear upto ultimate stress afterward determined by using the following equation,

$$
\left.\sigma=f_{t}\left(\frac{\varepsilon_{t}}{\varepsilon}\right)^{(0.7+10)}\right), \varepsilon_{t}=\frac{f_{t}}{E_{c}}
$$

\section{RESULTS AND DISCUSSIONS}

\subsection{Model Verification}

This study aimed to simulate the mechanical effects (generation of pressure, cracking etc.) of corrosion of reinforcements on the surrounding concrete. A uniform was considered to simplify the model. Due to this uniform corrosion, the problem was modelled as two-dimensional frame and formulate as plain strain problem. The 3-node linear plane strain triangle element was choosing to represent concrete.

An expansive pressure employs and increases gradually as the corrosion progresses (Shakib and Morshed, 2019). This pressure consequences a tensile stress on the cover concrete. When this pressure exceeds the resisting capacity (tensile strength) of the concrete material cover crack initiates. This pressure required to initiate crack is named as critical pressure. The model was validated by comparing the critical pressure with the experimental ones from Williamson and Clark (2000). The test specimens used by Williamson and Clark (2000) were cubical (with a side of $150 \mathrm{~mm}$ ) in shape with a hole at one corner as shown in Figure 4. The diameter of hole is $8 \mathrm{~mm}$. The hole represents as the reinforcement. Three different cover thicknesses were used in the experiment; $4 \mathrm{~mm}, 8 \mathrm{~mm}$, and $16 \mathrm{~mm}$ respectively. Since the expansive corrosion products exerts an outward pressure on the surrounding concrete, a uniform and gradually increasing hydraulic pressure was applied in the experimentation through the 
hole. In this study, to model this corrosion induced pressure an outward deformation was applied into the hole. The pressure required to crack the surrounding concrete was recorded for different cover thicknesses as shown in Figure 5. These pressures were compared with the experimental results obtained from Williamson and Clark (2000) as tabulated in Table 2. Critical pressures obtained from the model were comparable with the experimental ones (difference below 25\%). The model then used to simulate crack initiation and propagation in structures comprised of single and couple of bars.

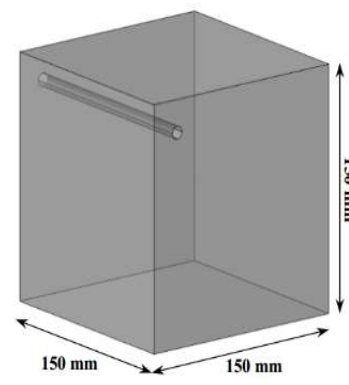

(a)

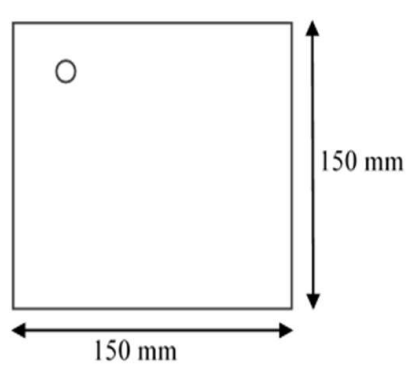

(b)

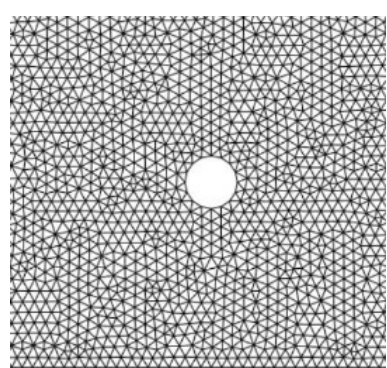

(c)

Figure 4: Specimens' dimensions tested by Williamson \& Clark, (2000) (a) 3D specimen (b) 2D formulation (c) Meshing

Table 2: The critical pressure for concrete cover cracking

\begin{tabular}{cccc}
\hline $\mathrm{c} / \mathrm{d}$ & $\mathrm{P}_{\max / \text { numerical }}(\mathrm{MPa})$ & $\mathrm{P}_{\max / \exp }(\mathrm{MPa})$ & $\Delta \mathrm{P}(\%)$ \\
\hline 0.5 & 2.70 & 2.65 & 1.9 \\
1.0 & 4.72 & 4.08 & 15.7 \\
2.0 & 6.00 & 7.71 & 22.2 \\
\hline
\end{tabular}

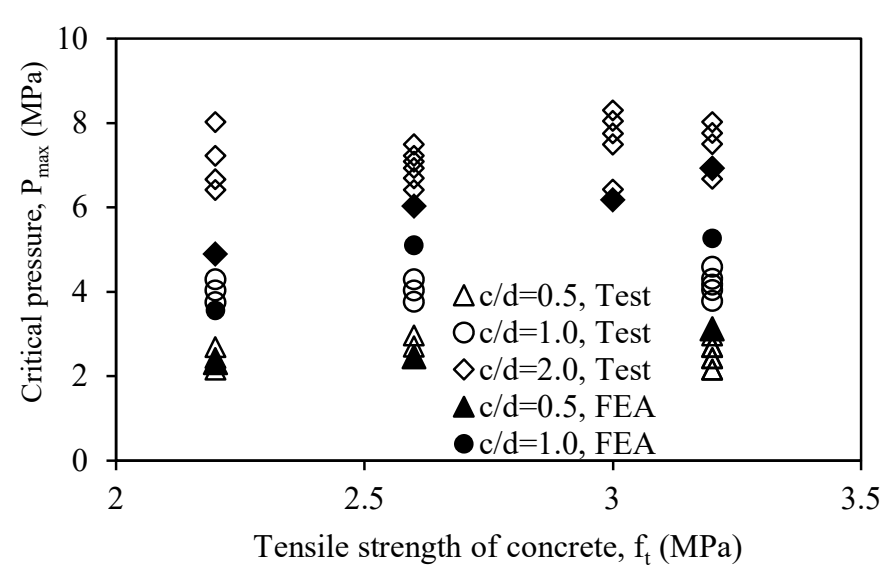

Figure 5: Comparison of results of finite-element analysis with test results from Williamson \& Clark (2000): for $\mathrm{d}=8 \mathrm{~mm}$

\subsection{Crack Initiation Mechanism}

In order to investigate the initiation and propagation of cracks due to corrosion of reinforcement, specimens with $200 \mathrm{~mm}$ x $200 \mathrm{~mm}$ with a clear cover of $20 \mathrm{~mm}, 37.5 \mathrm{~mm}, 50 \mathrm{~mm}$, and $75 \mathrm{~mm}$ respectively was modelled. From the analysis it was found that for a lower clear cover $(20 \mathrm{~mm}$ and $37.5 \mathrm{~mm}$ ), a heaving of cover concrete occurred as shown in Figure 6. Due to this bending effect, a tensile stress developed on the cover surface of the specimens. It consequence an initiation of crack at the cover surface and propagated inward. This phenomenon was observed experimentally by Shakib and Morshed (2019).

Whereas, for the clear covers of $50 \mathrm{~mm}$ and $75 \mathrm{~mm}$, crack initiated at the interface of reinforcement and concrete and propagated outwards as no heaving encountered. In this case, circumferential stress (tensile in character) developed due to the pressure was exceeded the tensile strength of concrete. Thus, crack initiated at the interface and propagates outward as shown in Figure 7. 

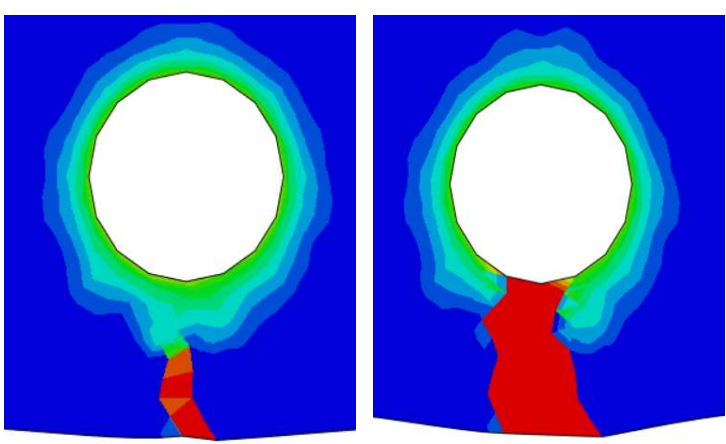

Cover $=20 \mathrm{~mm}$
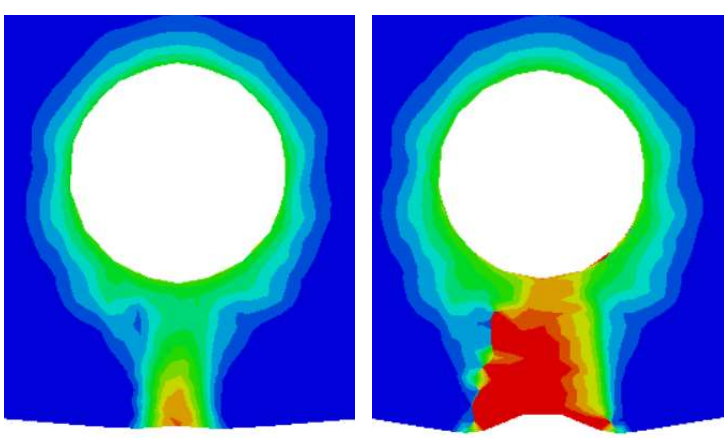

Cover $=37.5 \mathrm{~mm}$

Figure 6: Initiation and Propagation of Crack for cover $20 \mathrm{~mm}$ and $37.5 \mathrm{~mm}$
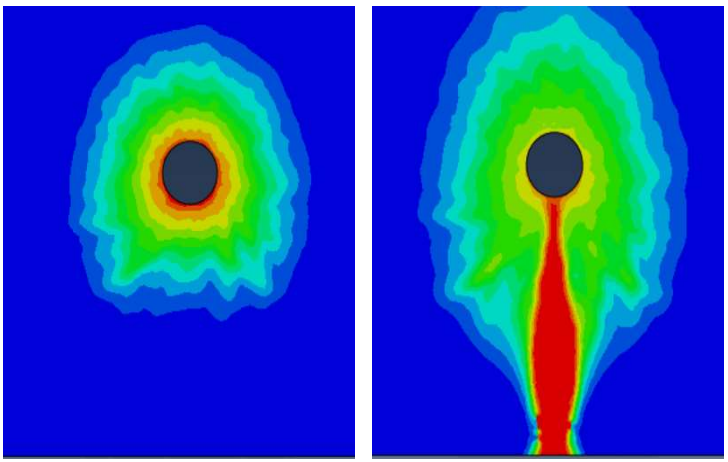

Cover $=50 \mathrm{~mm}$
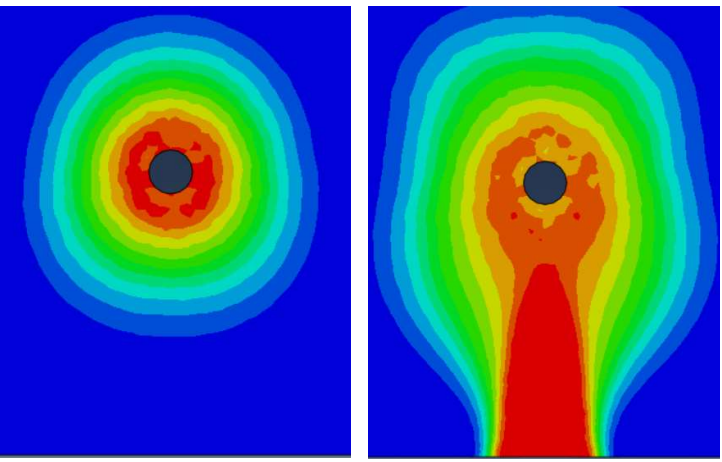

Cover $=75 \mathrm{~mm}$

Figure 7: Initiation and Propagation of Crack for cover $50 \mathrm{~mm}$ and $75 \mathrm{~mm}$

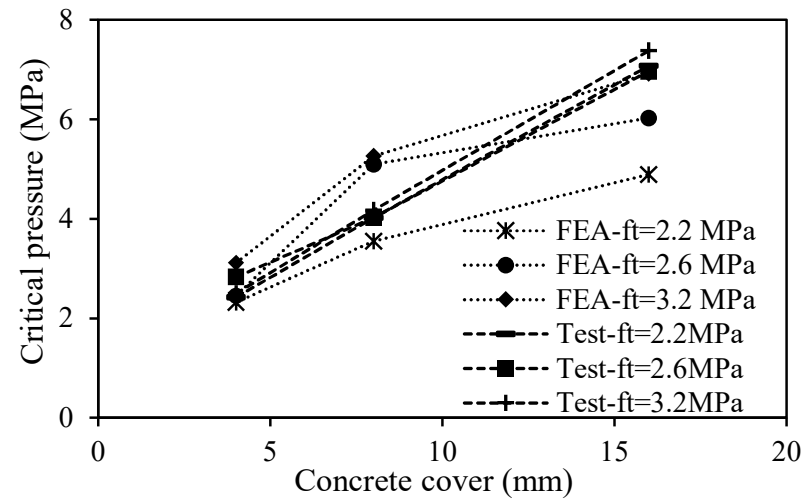

Figure 8: Effect of cover thickness on the critical pressure and comparison with the results of Williamson \& Clark, (2000)

\subsection{Relation of Concrete Cracking Pressure with Concrete Cover}

The variation of the critical pressures depending on the cover thicknesses are provided in Figure 8 . It can be seen from the figure that, with the increase in cover thicknesses, the critical pressure also increased. The model predicts the pressure required to cover cracking similar to that of test for cover thickness $4 \mathrm{~mm}$. On the other hand, for cover thickness $8 \mathrm{~mm}$, the model overestimates for higher tensile strengths $\left(f_{t}=2.6,3.0,3.2 \mathrm{MPa}\right)$ but underestimate for tensile strength $2.2 \mathrm{MPa}$. For cover thickness $16 \mathrm{~mm}$ model underestimate the pressures irrespective of the tensile strengths.

\subsection{Relation of Concrete Cracking Pressure with Bar Diameter}

Five finite element models are developed with varying bar (considered in model as a hole) diameters (d), from 10 $\mathrm{mm}$ to $25 \mathrm{~mm}$, where all other geometrical and material properties are kept constant $\left(\mathrm{C}=37.5 \mathrm{~mm}, f_{t}=3.4 \mathrm{MPa}\right)$. The pressure required for cracking of the concrete cover for each model is shown in Figure 9. As seen in the figure, the expansive pressure decreases as the bar diameter increases. By increasing of the bar diameter, the 
lateral surface of the hole increases which results in higher outward force and consequently lower required pressure for the cracking.

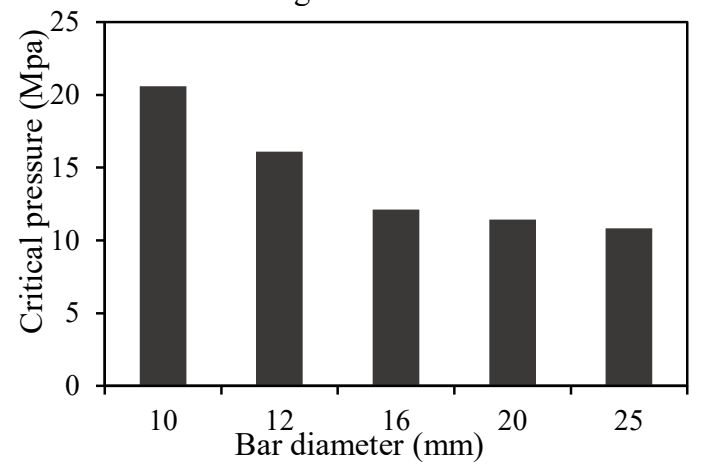

Figure 9: Effect of bar diameter on the required pressure for cracking

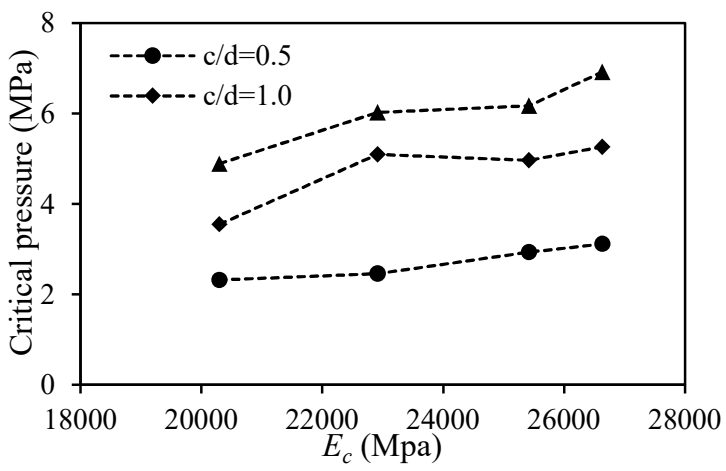

Figure 10: Effect of concrete modulus of elasticity on the required pressure

\subsection{Relation of Concrete Cracking Pressure with Modulus of Elasticity}

The variation of concrete cracking pressure with respect to modulus of elasticity of concrete has shown in figure 10. Williamson and Clark, 2000 didn't report the effect of modulus of elasticity of concrete on corrosion pressure. As shown in figure the higher the value of $E_{c}$ the pressure required to cover crack.
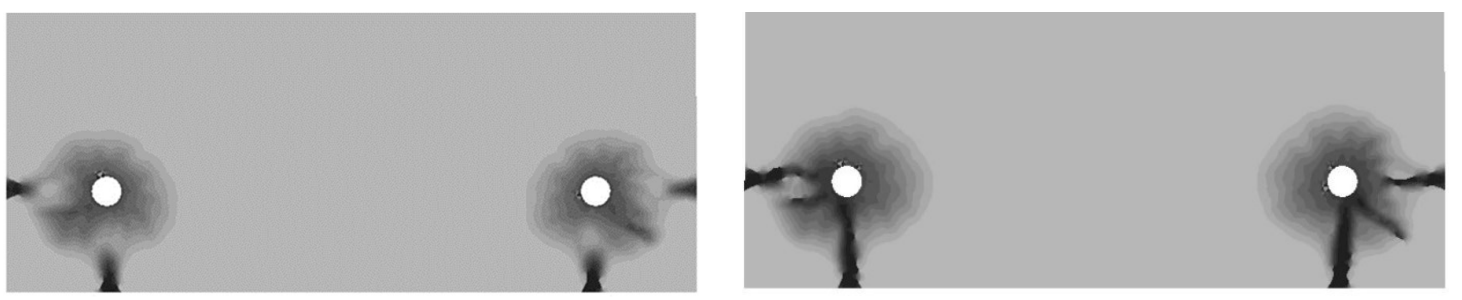

Figure 11: (a) Initiation and (b) Propagation of Cracks for 2-12 mm bar
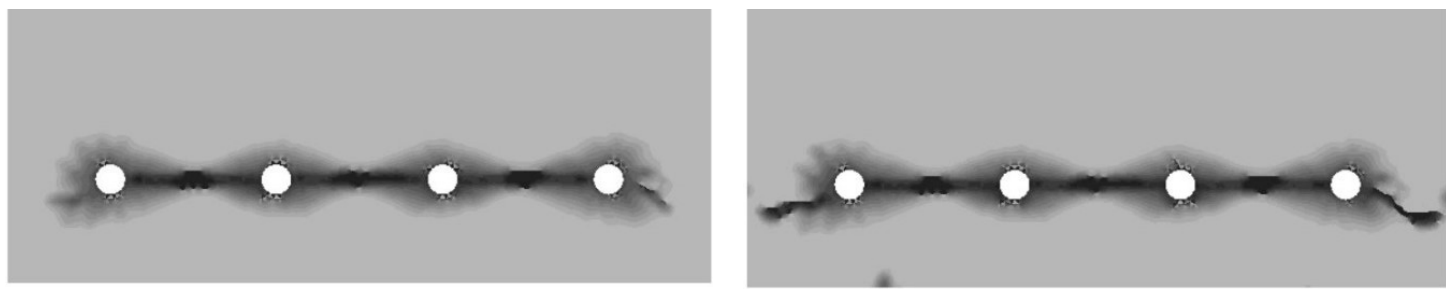

Figure 12: (a) Initiation and (b) Propagation of Cracks for 4-12 mm bar
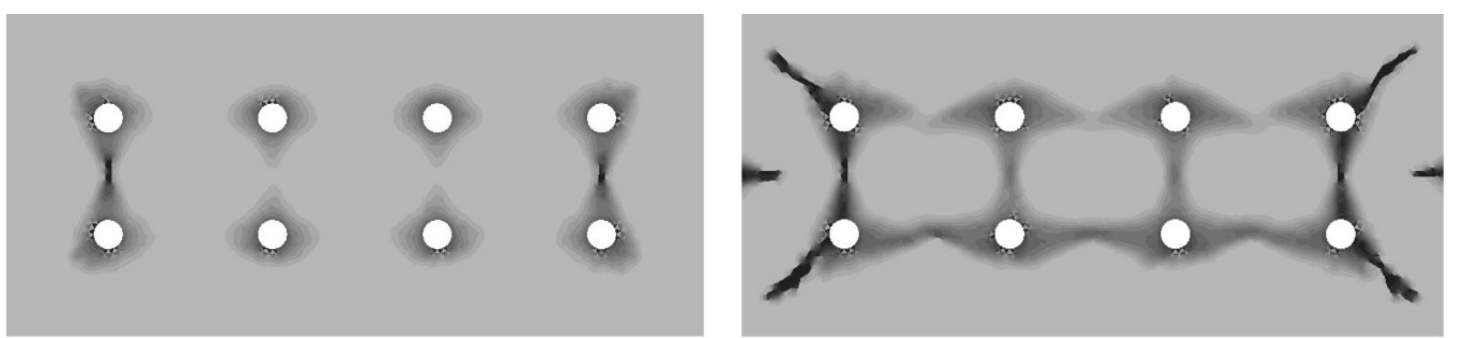

Figure 13: (a) Initiation and (b) Propagation of Cracks for 8-12 mm bar

\subsection{Patterns of Cracks in Beam}

The model was then used to anticipate the corrosion induced cracking of concrete beams (having cross section of $300 \mathrm{~mm} \times 500 \mathrm{~mm}$ ) comprised of a different number of bars (Ø-12). A clear cover of $37.5 \mathrm{~mm}$ was maintained for all the specimens. Three different configurations were investigated; 2 and 4 nos. of bars in single layer, and 8 nos. of bar in double layer. The patterns of cracks are shown in Figures 11-13. For 2-nos of bars, the crack pattern was similar to that of single bar; crack initiated at the cover surface. But, for 4 and 8-nos of bars, crack occurred 
in between the reinforcements first and then propagated to the cover surfaces. Pressure generally release through shortest distance from the point of generation. The distance between the reinforcements was shorter than the cover thickness. In addition to the distance measurement, the pressure was generated from both direction. This may be the reason behind these crack patterns for 4 and 8 nos. of bars.

\section{CONCLUSIONS}

In this paper, corrosion induced expansive pressure was modelled through a finite element software Abaqus. Rebar corrosion was simulated as simplified 2D formulation. The model successfully depicted the crack initiation mechanisms depending on the cover thicknesses. For relatively thinner concrete covers of $20 \mathrm{~mm}$ and $37.5 \mathrm{~mm}$, initiation of cracks was found from the concrete surface and propagated inward. On the other hand, for thicker concrete covers of $50 \mathrm{~mm}$ and $75 \mathrm{~mm}$, cracks were found to initiate at the interface of steel reinforcement and concrete. The model was also used to predict the cracking patterns of beams comprised of three different combinations of bars. For 2-nos of bars, crack initiated at the cover surface. But, for 4 and 8-nos of bars, crack occurred in between the reinforcements first and then propagated to the cover surfaces. It was found that critical pressure increased with increase of clear cover, whereas, decreased with the increase in bar diameter.

\section{REFERENCES}

Bazant, Z. P., 1979. Physical model for steel corrosion in concrete sea structures - theory, Journal of the Structural Division-ASCE, 105(6), 1137-1153.

Mundra, S., Criado M., Bernal S. A., and Provis J. L., 2017. Chloride-induced corrosion of steel rebars in simulated pore solutions of alkali-activated concretes, Cement and Concrete Research, 100, 385-397. https://doi.org/10.1016/j.cemconres.2017.08.006.

Glasser, F. P., and Sagoe-Crentsil K. K., 1989. Steel in concrete: part ii electron microscopy analysis, Magazine of Concrete Research, 41, (149), 213-220. https://doi.org/10.1680/macr.1989.41.149.213.

Val, D. V., Chernin L., and Stewart M. G., 2009. Experimental and numerical investigation of corrosion-induced cover cracking in reinforced concrete structures, Journal of Structural Engineering, 135(4), 376-385. https://doi.org/10.1061/(ASCE)0733-9445(2009)135:4(376).

Pantazopoulou, S. J., and Papoulia K. D., 2001. Modeling cover-cracking due to reinforcement corrosion in rc structures, Journal of Engineering Mechanics, 127(4), 342-351.

Liu, Y., and Weyers R. E., 1998. Modeling the time-to-corrosion cracking in chloride contaminated reinforced concrete structures, ACI Materials Journal, 95(6), 675-680.

Bhargava, K., Ghosh A. K., Mori Y., and Ramanujam S., 2006. Model for cover cracking due to rebar corrosion in rc structures, Engineering Structures, 28(8), 1093-1109.

Shakib, S., and Morshed A. Z., 2019. Experimental investigation on crack initiation and propagation due to corrosion of reinforcement, Advances in Civil Engineering Materials, 8(1), 688-698. https://doi.org/ 10.1520/ACEM20190161

Dagher, H. J., and Kulendran S., 1987. Finite element modeling of corrosion damage in concrete, ACI Structural Journal, 89(6).

Du, Y. G., Chan A. H. C., and Clark L. A., 2006. Finite element analysis of the effects of radial expansion of corroded reinforcement, Computers \& Structures, 84(13-14), 917-929.

Popovics, S., 1973. A numerical approach to the complete stress-strain curve of concrete, Cement and Concrete Research, 3(5), 583-599.

Lee, J. and Fenves G. L., 1998. Plastic-damage model for cyclic loading of concrete structures, Journal of Engineering Mechanics, 124(8), 892-900.

Lubliner, J., Oliver J., Oller S., and Oñate E., 1989. A plastic-damage model for concrete, International Journal of Solids and Structures, 25(3), 299-326.

(C) 2021 the Authors. Journal of Engineering Science published by Faculty of Civil Engineering, Khulna University of Engineering \& Technology. This is an open access article under the terms of the Creative Commons AttributionNonCommercial-NoDerivatives License, which permits use and distribution in any medium, provided the original work is properly cited, the use is non-commercial and no Modifications or adaptations are made. 